\title{
Estratégias para a apresentação da responsabilidade social em sites de organizações privadas
}

\author{
Strategies for presentation of the social responsibility \\ in private organizations websites
}

\author{
Fabiane Sgorla $^{[a]}$, Maria Ivete Trevisan Fossá ${ }^{[b]}$
}

[a] Mestre em Comunicação Midiática pela Universidade Federal de Santa Maria (UFSM), integrante do Grupo de Pesquisa Comunicação Institucional e Organizacional (UFSM/CNPq), Santa Maria, RS - Brasil, e-mail: fabisgorla@hotmail.com

[b] Mestre em Comunicação Midiática pela Universidade Federal de Santa Maria (UFSM), integrante do Grupo de Pesquisa Comunicação Institucional e Organizacional (UFSM/CNPq), Santa Maria, RS - Brasil, e-mail: fabisgorla@hotmail.com

\section{Resumo}

No contexto das organizações, os sites são considerados espaços estratégicos para a apresentação das mais diferenciadas informações. Este artigo apresenta os resultados de uma pesquisa que buscou identificar e analisar as estratégias de apresentação das informações organizacionais referentes à responsabilidade social por meio dos links presentes em 17 sites de organizações do ramo de calçados, sediadas no Estado do Rio Grande do Sul. Os resultados permitiram a categorização de 7 estratégias, as quais são apresentadas na sequência: "apoios e ações", "balanço social", "notícias", "organização", "patrocínios", "responsabilidade social" e "responsabilidade ambiental". Observamos que são múltiplas as possibilidades de apresentação da responsabilidade social em sites organizacionais e as estratégias utilizadas parecem estar vinculadas ao entendimento que cada organização possui acerca da responsabilidade social.

Palavras-chave: Sites organizacionais. Estratégias. Responsabilidade social. Organizações privadas.

\begin{abstract}
In the context of the organizations the websites are considered strategic spaces forpresentation of different information. This article presents the results of a research which identified and analyzed presentation's strategies of information about corporate social responsibility through links in 17 websites of the companies of the footwear sector, located in Rio Grande do Sul, Brazil. The results present 7 categories of strategies: "support and activities", "social report", "news, company", "sponsorship", "social responsibility" and "environmental responsibility". We notice that the possibilities of presentation of the social responsibility are multiple and these are tied with the concepts of social responsibility assumed by each organization.
\end{abstract}

Keywords: Organizational websites. Strategies. Corporate social responsibility. Private organization. 


\section{Introdução}

No panorama atual, os artifícios da internet, ligados principalmente ao sistema da web (world wide web-www - rede de alcance mundial), tais como os sites, possuem um papel importante na visibilidade e na comunicação das organizações privadas e são cada vez mais frequentes nesse contexto. Por meio da funcionalidade e da lógica singular dos links, o site organizacional permite a operacionalização de uma série de estratégias para a apresentação das informações organizacionais, de acordo com os interesses de cada organização.

Dentre as várias informações que podem estar presentes nos sites organizacionais, enfatizamos aqui as informações referentes à responsabilidade social organizacional. No cenário das organizações privadas, as informações referentes à responsabilidade social têm origem em valores, processos e práticas organizacionais que não objetivam o lucro, não são regidas por leis, buscam o bem-estar e a qualidade de vida dos indivíduos de maneira global e, dessa forma, carregam consigo temáticas humanistas, solidárias e ambientais, as quais, na maioria das vezes, são valorizadas pelos públicos.

A proposta deste estudo é identificar e analisar as principais estratégias de apresentação das informações referentes à responsabilidade social em sites de organizações privadas, a partir da verificação dos títulos dos links em que essas informações se encontram. Para o estudo empírico, destacamos uma amostragem de 17 sites de organizações privadas do ramo de calçados, sediadas no Estado do Rio Grande do Sul, e que no mês de julho de 2008 apresentaram informações relacionadas à responsabilidade social organizacional.

Este estudo, por meio principalmente dos resultados apresentados, colabora com perguntas e respostas acerca das variadas formas de apresentação de informações organizacionais em sites de organizações privadas. Contribui ainda com as discussões acerca da importância das informações referentes à responsabilidade social no quadro de informações organizacionais apresentadas nos sites de organizações privadas.

Dividimos este artigo em três partes. Primeiramente, buscamos entender o conceito de responsabilidade social organizacional a partir dos aportes do Instituto Ethos de Empresas e Responsabilidade Social (2007, 2010). O segundo tópico apresenta as estratégias do estudo empírico, apresentando o percurso metodológico do estudo. O terceiro tópico apresenta as principais estratégias para a apresentação da responsabilidade social nos sites organizacionais observados nesta investigação. As considerações finais retornam algumas discussões surgidas na caminhada da pesquisa e apontam certas conclusões.

\section{O entendimento de responsabilidade social organizacional}

Segundo o Instituto Ethos de Empresas e Responsabilidade Social (2010), a responsabilidade social empresarial (ou organizacional) é a forma de gestão que se define pela relação ética e transparente da empresa com todos os públicos por meio do estabelecimento de metas que impulsionem o desenvolvimento sustentável da sociedade, preservando recursos ambientais e culturais para as gerações futuras, respeitando a diversidade e estimulando a redução das desigualdades sociais. Quanto às principais características da responsabilidade social organizacional, o Instituto Ethos (2007, p. 7-8) destaca:

a) Transparência: divulgando informações, decisões e intenções de maneira clara e acessível a todos os públicos que se relacionam com a empresa.

b) Estabelecimento de compromissos públicos: assumindo publicamente os compromissos que a empresa tem, sejam relacionados ao seu público interno, ao futuro, à manutenção de recursos naturais, à promoção da diversidade.

c) Envolvimento com instituições que representam interesses variados: procurando contato $\mathrm{e}$ diálogo com organizações e especialistas que colaborem com a empresa para lidar com seus dilemas.

d) Capacidade de atrair e manter talentos: apresentando-se como uma alternativa profissional que possa também atender aos interesses de cidadão do profissional.

e) Alto grau de motivação e comprometimento dos colaboradores: envolvendo todos os colaboradores internos e fornecedores com a gestão da RSE, demonstrando coerência em seus compromissos. 
f) Capacidade de lidar com situações de conflito: demonstrando disposição para a investigação e o diálogo, desenvolvendo processos que previnam situações de risco, aprofundando contato com redes de organizações e formadores de opinião, usando de transparência nessas relações.

g) Estabelecimento de metas de curto e longo prazo: introduzindo realmente aspectos de responsabilidade social na gestão da empresa, com todas as características que outros indicadores de performance possuem.

b) Envolvimento da direção da empresa: comprovando claramente o entendimento estratégico que tem dessas questões. Em geral, a empresa tem um ou mais colaboradores que dedicam seu tempo a questões de responsabilidade social.

Em cada organização, as práticas de responsabilidade social, bem como as informações referentes a elas, possuem aspectos diferenciados relacionados a questões como: objetivos organizacionais, situação financeira, setor e local de atuação, abrangência geográfica, tipo de produto que fabrica, tipo de serviço que oferece, aspectos ambientais envolvidos no sistema de produção, número de funcionários, públicos que a organização quer atingir, entre outros.

Destacamos aqui três formatos em que, geralmente, a responsabilidade social, quando é voltada para a comunidade, é apresentada: ações sociais, projetos sociais e patrocínios. As ações sociais caracterizam-se como atividades pontuais, em que a organização se mobiliza para atender a alguma necessidade momentânea da comunidade em áreas tais como: saúde, educação, assistência social, alimentação, entre outras. Alguns exemplos disso são as campanhas de arrecadação de brinquedos para crianças carentes na época do Natal e o apoio (em dinheiro ou produtos) a comunidades atingidas por desastres naturais, como enchentes ou vendavais.

Diferente das ações sociais, que são momentâneas, os projetos sociais remetem a algo estruturado e sistemático. Esses projetos podem ser planejados, executados e mantidos financeiramente pela organização e podem visar a atender tanto os funcionários quanto a comunidade. Muitos projetos são encabeçados pelas chamadas fundações, que são gerenciadas pelas próprias organizações. Por meio das fundações, as organizações promovem, por exemplo, projetos culturais, de investigação científica, artística e literária, de preservação ambiental, etc.

É possível também observar a atuação das organizações a partir do apoio (em dinheiro, força de trabalho ou outras espécies, de modo formal ou informal) a projetos criados por outras organizações privadas, por organizações não governamentais ou mesmo porórgãos governamentais. Como contrapartida, as organizações apoiadoras recebem certificados de participação ou têm suas marcas associadas às atividades desses projetos.

Certos tipos de patrocínio (no caso patrocínios sociais) estão ligados à participação organizacional em ações ou projetos sociais externos à organização, por meio do repasse de dinheiro. O patrocínio geralmente se realiza de modo formal e está conectado à contrapartida em publicidade. É nessa questão que reside a polêmica, pois em algumas organizações o patrocínio passa a ter como foco primordial o "marketing social" e as relações comerciais em detrimento de seu foco social-assim, a essência altruísta do ato de patrocinar, como uma atividade socialmente responsável, ficaria em segundo plano. $\mathrm{Na}$ ordem dessa discussão, Bueno (2007) considera que:

muitos projetos de marketing social têm como inspiração maior (às vezes única) alavancar negócios e vendas, apenas tangenciando o social como forma de ludibriar o consumidor e o cidadão de maneira geral. Geralmente, tem uma duração efêmera (enquanto dura a campanha ou a ação de marketing) e que não se sustentam a longo prazo, ficando evidente o seu caráter oportunista. Com isso, não estamos negando, aqui, a importância do marketing social, mesmo porque há muitas ações realmente sérias e absolutamente necessárias no campo da cultura, do esporte, da saúde, da educação, etc. (BUENO, 2007, p. 180).

Contudo, apesar de muitas vezes o patrocínio estar ligado ao marketing, é inegável o valor de suas consequências para a sociedade, por meio, por exemplo, do incentivo a eventos culturais, artísticos, educacionais, esportivos ou do investimento no desenvolvimento de atletas, em patrimônios históricos, na publicação de livros e outros. 
Em muitos, quando a organização apresenta a sua responsabilidade social, a ação social, o projeto social e o patrocínio podem aparecer sob a mesma expressão "ações sociais", isso porque, no plano prático, podem ser consideradas práticas (ações) que envolvem questões ligadas à responsabilidade social da organização. Entretanto, o Instituto Ethos (2007, p. 6) ressalva que "as ações sociais de uma empresa só podem ser consideradas RSE (responsabilidade social empresarial) se fizerem parte de uma série de outras iniciativas".

Dentre as várias formas que as organizações utilizam para divulgar a sua responsabilidade social, o balanço social, ou relatório social, merece certo destaque. Segundo o Instituto Brasileiro de Análises Sociais e Econômicas (Ibase), o balanço social "é o registro das ações que marcam a responsabilidade social da organização, onde estão explícitas as iniciativas de caráter social, os resultados atingidos e os investimentos realizados". Graças à sua estrutura e aos critérios exigidos pelos modelos mais usados, com informações na modalidade quantitativa e qualitativa, a construção de um balanço social é uma atividade trabalhosa e que exige o envolvimento de muitos, tanto do âmbito interno quanto do âmbito externo da organização. Quanto ao formato, o balanço social pode apresentar-se como um informativo ou revista impressa, aparecer de modo resumido em jornais massivos, pode ser incluído em sites, etc.

Atualmente, os sites aparecem como espaços midiáticos estratégicos para a apresentação da responsabilidade social. Por suas características e fun- cionalidade, como o sistema de links, o site organizacional possibilita a criação de diferenciadas estratégias para a apresentação das informações organizacionais. Essa multiplicidade de combinações possíveis permite que a apresentação da responsabilidade social proposta nos sites possa ser pensada estrategicamente e planejada em detalhes pelas organizações.

\section{Percurso metodológico do estudo empírico}

Tendo em vista que a proposta deste estudo é identificar e analisar as principais estratégias de apresentação das informações referentes à responsabilidade social em sites de organizações privadas, destacamos uma amostragem de 17 sites de organizações. Os sites em questão são de organizações privadas do ramo de calçados, sediadas no Estado do Rio Grande do Sul, e que apresentam links com informações referentes à responsabilidade social. Esta pesquisa foi realizada em julho de 2008 e teve abordagem quantitativa e qualitativa, por meio do método descritivo e interpretativo.

As buscas nos sites foram baseadas na presença das expressões "responsabilidade social", "responsabilidade ambiental", "responsabilidade socioambiental", "socialmente responsável", "ambientalmente responsável" e "socioambientalmente responsável", bem como a partir da identificação das palavras e expressões que, de acordo com os principais aspectos sobre a responsabilidade social apontados pelo Instituto Ethos (2007), podem indiciar a responsabilidade social. O Quadro 1, apresentado a seguir, mostra as principais palavras ou expressões que indiciam a responsabilidade social.

Quadro 1 - Palavras ou expressões que indiciam a responsabilidade social

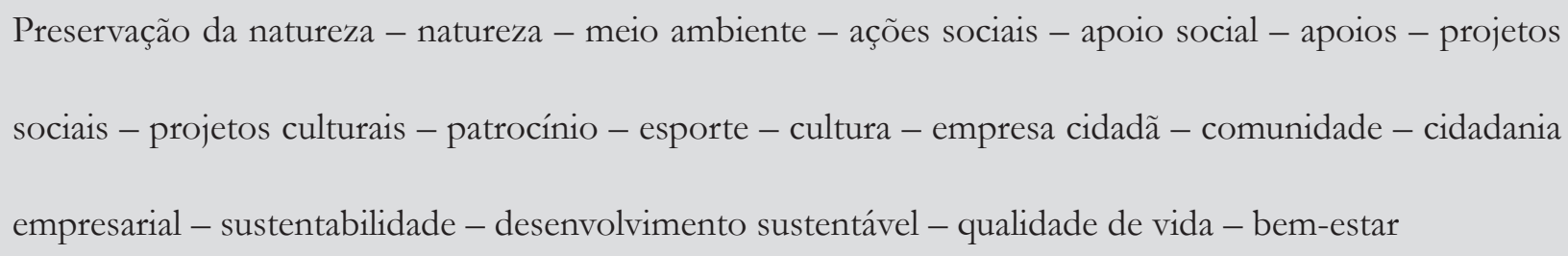

Fonte: Adaptado de INSTITUTO ETHOS, 2007; BUENO, 2003. 
Com a clareza de que, no perímetro dos sites organizacionais, algumas das palavras ou expressões, destacadas no Quadro 1, pudessem surgir em contextos variados, nos preocupamos em verificar a associação (explícita ou implícita) delas exclusivamente com a prática da responsabilidade social organizacional. A partir da localização das informações referentes à responsabilidade social buscamos identificar os links em que elas se encontram.

Cabe aqui também uma ressalva. Ao contrário do Instituto Ethos (2007), que defende a ética como um dos indicadores de responsabilidade social, nesta pesquisa optamos por não pesquisar as questões relacionadas a ela. Isso se justifica razão da necessidade de uma investigação específica e aprofundada sobre a ética e suas implicações, além de não se ter como crença que o comportamento ético seja um diferencial apenas para organizações com características socialmente responsáveis - e sim que a ética é algo intrínseco a todo ato organizacional.

No momento da compilação dos resultados utilizamos a categorização, que é uma das estratégias da análise de conteúdo. Wilson Corrêa da Fonseca Júnior (2005, p. 298) afirma que categorizar "consiste no trabalho de classificação e reagrupamento das unidades de registro em número reduzido de categorias, com o objetivo de tornar inteligível a massa de dados e sua diversidade". Com base nisso, as categorias foram criadas a partir da observação das similaridades das palavras ou expressões que sinalizam os links em que se localizam as informações referentes à responsabilidade social. Logo, consideramos para este estudo que cada categoria representa um tipo de estratégia para a apresentação das informações referentes à responsabilidade social.

Para categorizar as estratégias de apresentação das informações nos sites organizacionais, estudamos as seções básicas que compõem a home page (página inicial) de um site. O pesquisador José Benedito Pinho (2003,p. 102-104) aponta como principais seções: sobre a empresa; produtos e serviços; suporte técnico; pedido de compra e informações; serviço ao consumidor; notícias e novidades; sistema de busca; e mapa do site.

\section{Estratégias para a apresentação da responsabilidade social em sites de organizações privadas}

O Quadro 2 retrata o resumo dos resultados da pesquisa por meio das categorias, da relação de incidência de sites por categoria (a partir do grupo de 17 sites investigados), da incidência de categoria por site e, em seguida, são apresentadas algumas reflexões acerca dos resultados. Cada um dos 17 sites de organizações do ramo de calçados sediadas no Rio Grande do Sul -, destacados para esta investigação apresentam informações referentes à responsabilidade social e são retratados aqui a partir das letras da sequência alfabética.

Quadro 2 - Estratégias de apresentação das informações referentes à responsabilidade social nos sites organizacionais, por categorias

(Continua)

\begin{tabular}{ccccccc}
\hline Categorias \\
\hline Sites organizacionais \\
\hline
\end{tabular}


Quadro 2 - Estratégias de apresentação das informações referentes à responsabilidade social nos sites org nizacionais, por categorias

\begin{tabular}{|c|c|c|c|c|c|c|c|c|}
\hline C & & & & & $\mathrm{X}$ & & & 1 \\
\hline $\mathbf{D}$ & & & & $\mathrm{X}$ & & & & 2 \\
\hline $\mathbf{E}$ & & & $\mathrm{X}$ & $\mathrm{X}$ & & & $\mathrm{X}$ & 3 \\
\hline $\mathbf{F}$ & & & & $\mathrm{X}$ & & & & 1 \\
\hline G & & & & $\mathrm{X}$ & & & & 1 \\
\hline $\mathbf{H}$ & & & $\mathrm{X}$ & $\mathrm{X}$ & & & & 2 \\
\hline I & & & & & & & $\mathrm{X}$ & 1 \\
\hline $\mathrm{J}$ & $\mathrm{X}$ & & & & & & & 1 \\
\hline $\mathbf{L}$ & & & & & & $\mathrm{X}$ & $\mathrm{X}^{*}$ & 2 \\
\hline $\mathbf{M}$ & $\mathrm{X}$ & & & & & $\mathrm{X}$ & & 2 \\
\hline $\mathbf{N}$ & & & & & & & $\mathrm{X}$ & 1 \\
\hline $\mathbf{O}$ & & & & & & $\mathrm{X}$ & $\mathrm{X}$ & 2 \\
\hline $\mathbf{P}$ & & $\mathrm{X}$ & $\mathrm{X}$ & $\mathrm{X}$ & & $\mathrm{X}$ & & 4 \\
\hline Q & & & & $\mathrm{X}$ & & & & 1 \\
\hline $\mathbf{R}$ & & & & $\mathrm{X}$ & & & & 1 \\
\hline Incidência de sites por categoria & 2 & 1 & 3 & 9 & 1 & 5 & 5 & \\
\hline $\begin{array}{c}\text { Incidência em porcentagem (\%) } \\
\text { sob os } 17 \text { sites }\end{array}$ & $11,76 \%$ & $5,88 \%$ & $17,64 \%$ & $52,95 \%$ & $5,88 \%$ & $29,41 \%$ & $29,41 \%$ & \\
\hline
\end{tabular}

Fonte: Dados da pesquisa.

Legenda: $*$ = Nesse site organizacional, o link "responsabilidade ambiental” sinaliza uma página em branco. Como o objetivo deste estudo é identificar as estratégias de apresentação das informações referentes à responsabilidade social a partir das palavras ou expressões que sinalizam os links, e não o conteúdo apresentado em cada link, a falta de conteúdo não modificou os resultados.

Apoios e ações: incidência de dois, ou 11,76\%, no grupo de 17 sites organizacionais. Essa categoria foi configurada a partir da constatação da presença de informações organizacionais referentes à responsabilidade social em links sinalizados pelas expressões "ação social" e "apoio ao esporte". Observamos que um dos sites estudados apresenta tanto um link sinalizado pela expressão "responsabilidade social" quanto um link sinalizado pela expressão "apoio ao esporte", o que dessa forma transparece a intenção de fazer uma distinção entre responsabilidade social e os apoios prestados. O apoio ao esporte pode ser entendido como uma parte da responsabilidade social, não obstante, somente o apoio, como ação pontual, não pode dar para determinada organização o destaque de socialmente responsável.

Balanço social: incidência de um caso, ou 5,88\%, no grupo dos 17 sites organizacionais. Essa estratégia foi observada a partir da verificação do caso de um link sinalizado pela expressão "Relatório
Social 2005". Ao acessar o link, encontramos uma versão do balanço social dessa organização em formato PDF (Portable Document Format - Formato de Documento Portável). Levando em conta que o desenvolvimento de um balanço social é uma atividade considerada trabalhosa, que depende da participação de vários setores da organização e que nem a sua produção e nem publicação são obrigatórias, as organizações que o elaboram e o publicam em seus sites parecem estar dedicadas a divulgar sua responsabilidade social.

Notícias: incidência de três casos, ou 17,64\%, no grupo dos 17 sites organizacionais investigados. Essa categoria compreende os casos em que as informações referentes à responsabilidade social aparecem em formato de notícia ou release e em links sinalizados a partir de palavras ou expressões como: "assessoria de imprensa", "news" e "na mídia". O estudioso das teorias da notícia, Luiz Gonzaga Motta, considera que "para ganhar o estatuto de notícia um fato deve 
passar por uma negociação que envolve o próprio acontecimento e seus atributos e algumas exigências decorrentes da natureza do trabalho jornalístico. É dessa negociação que começa a tomar forma a notícia" (MOTTA, 1997, p. 310). Ao apreciar as considerações de Motta (1997), Graça Monteiro (2003, p. 144) salienta que os fatos transformados em notícia associam "atributos como excepcionalidade, atualidade, proeminência, relevância social, impacto e significância". Logo, constatamos que, ao surgirem nos sites no formato de notícia, as informações referentes à responsabilidade social adotam elementos típicos da natureza jornalística, apresentando significações diferenciadas das demais informações circulantes nos sites, podendo até ampliar sua credibilidade perante os públicos. Com essa estratégia de apresentação de sua responsabilidade social, as organizações parecem também querer chamar a atenção de jornalistas e dos meios de comunicação.

Organizaçôes: incidência de nove, ou 52,95\%, no grupo de 17 sites organizacionais. Observamos que, na maior parte do grupo de sites investigados, as informações referentes à responsabilidade social surgem inseridas em links sinalizados por palavras ou expressões, tais como: "empresa", "quem somos", "institucional", "apresentação", "perfil" ou ainda por meio do próprio nome da organização. Segundo Pinho (2003, p. 102), na seção do site que fala sobre a organização ("sobre a empresa") pode aparecer "o histórico da organização, sua missão, a filosofia de negócio etc. A empresa deve colocar-se para o consumidor evidenciando as qualidades que a tornam superior às demais concorrentes". Ao utilizar essa estratégia, as organizações parecem querer mostrar que a sua responsabilidade social vai além de uma prática pontual e que está imbricada nos processos de gestão organizacional, como um elemento do negócio - como parte do perfil da organização.

Patrocínios: incidência de um caso, ou 5,88\%, no grupo dos 17 sites organizacionais investigados. Essa categoria surgiu a partir de um caso em que notamos presença de informações referentes à responsabilidade social em um link sinalizado pela palavra "patrocínio". Na maioria das vezes, o patrocínio é visto unicamente como uma estratégia de marketing, contudo, entendemos aqui que o ato de patrocinar pode ser tido também como uma prática de responsabilidade social, sobretudo, pelo resultado que essas práticas apresentam quando extrapolam seu intuito mercadológico e trazem o bem social.
Responsabilidade social: incidência de cinco, ou 29,41\%, no grupo de 17 sites organizacionais pesquisados. Essa categoria foi criada a partir dos casos em que as informações referentes à responsabilidade social aparecem em links sinalizados pela expressão "responsabilidade social". Ao utilizar essa estratégia, a organização parece conferir certo destaque à sua responsabilidade social, explicando suas práticas com mais detalhes. Nesse momento, a organização não associa a sua responsabilidade social nem ao seu perfil organizacional nem aos produtos fabricados ou serviços. Assim, a responsabilidade social parece ser vista pela organização com certa autonomia diante das demais informações organizacionais.

Responsabilidade ambiental: incidência de cinco casos, ou 29,41\%, no grupo dos 17 sites organizacionais investigados. Compreende os momentos em que as informações referentes à responsabilidade social aparecem com enfoque exclusivo nas questões ambientais e se fazem presentes em links sinalizados a partir de palavras ou expressões como "responsabilidade ambiental" e "meio ambiente". Incluímos nessa categoria o caso do site organizacional identificado no Quadro 2 pela letra F, o qual utiliza o próprio espaço do site para exercer a responsabilidade social à medida que apresenta um "jogo interativo" de educação ambiental, que traz dicas sobre a preservação ambiental. $\mathrm{O}$ site identificado pela letra $\mathrm{O}$, bem como o identificado pela L, além de apresentarem links exclusivos para as questões ambientais, apresentam também links sinalizados pela expressão "responsabilidade social", com isso as organizações parecem ver suas práticas de responsabilidade social segmentadas em dois enfoques: o social - relativo às questões humanas; e o ambiental - relativo ao meio ambiente.

Dentre os 17 sites observados, destacamos dois deles por apresentarem características que os diferenciam dos demais. O site identificado pela letra $\mathrm{N}$, além de apresentar elementos que o associam à categoria "responsabilidade ambiental", mostra as informações referentes à responsabilidade social por meio de um site específico - caso em que a responsabilidade social parece possuir maior importância diante do quadro de informações. Já o site identificado pela letra $\mathrm{P}$ se destaca por apresentar a maior variedade de estratégias para a apresentação da responsabilidade social, sendo associado a quatro categorias: "balanço social", "notícias", "organização" e "responsabilidade social". 


\section{Considerações finais}

O diagnóstico das principais estratégias de apresentação das informações referentes à responsabilidade social (observadas a partir das similaridades das palavras ou expressões que sinalizam os links em que se encontram essas informações), aplicadas nos 17 sites investigados, permitiu o estabelecimento de sete categorias, as quais compreendem: "apoios e ações", "balanço social", "notícias”, "organização", "patrocínios", "responsabilidade social" e "responsabilidade ambiental". A significativa incidência $(52,95 \%)$ das informações referentes à responsabilidade social sob a categoria "organização" revela pistas de que essas informações são hoje relevantes na construção do perfil das organizações citadas.

Notamos que cada estratégia apresentada pelas organizações em seus respectivos sites não parece ter sido escolhida ao acaso, de modo aleatório, mas sim estrategicamente - parece ter sido feita a partir de escolhas norteada pelos propósitos de cada organização. Esse movimento estratégico é observado, por exemplo, na seleção de determinadas informações referentes à responsabilidade social em detrimento de outras, na associação com diferentes informações organizacionais, no formato que essas informações assumem (som, imagem, texto verbal, etc.), nas diferentes posições na estrutura dos sites, na escolha das palavras e expressões que sinalizam os links, entre outros.

Se o desenho das estratégias para divulgar a responsabilidade social nos sites organizacionais é variado, é estratégico e segue as propostas de cada organização, então esse desenho pode revelar indícios relativos a aspectos como: a intenção da organização ao apresentar essas informações; o conceito de responsabilidade social que a organização assume; os significados e os sentidos que a organização quer associar à sua responsabilidade social; a posição da organização diante de questões sociais e ambientais; a importância da responsabilidade social para a organização; a importância das práticas socialmente responsáveis em relação a outras práticas organizacionais; a importância da divulgação midiática da responsabilidade social; entre outros. Assim, todos os imbricamentos entre forma e conteúdo influenciam tanto no sentido de potencializar a divulgação da responsabilidade social como no sentido de minimizála diante das demais informações organizacionais presentes no perímetro dos sites.
No entanto, por mais que a organização esquematize de modo estratégico a apresentação de sua responsabilidade social de acordo com seus objetivos, é imprescindível levar em consideração o papel do público que se quer atingir. É o público que toma a iniciativa e elege acessar ou não determinado site organizacional, é o público que opta se irá ou não clicar nos links e percorrer os caminhos desenhados pela organização e, por sua vez, se irá ou não observar as informações disponíveis. Portanto, o conhecimento das características dos públicos é essencial para que a organização possa planejar a divulgação da sua responsabilidade social.

Entendemos, ainda, que somente a apresentação das informações referentes à responsabilidade social nos sites da organização pode não surtir o efeito desejado pelas organizações. Uma discussão maior reside hoje na necessidade da ativação de processos de interação a partir da temática da responsabilidade social, pois é por meio de artifícios que instiguem a relação, a troca e o intercâmbio entre públicos e organização que esta poderá ser realmente percebida como socialmente responsável. Desse modo, o desafio tem sido a elaboração de estratégias que objetivem a participação dos públicos nas questões relacionadas à atuação socialmente responsável das organizações. Essas estratégias podem se dar desde o estímulo à integração dos públicos nos projetos socialmente responsáveis encabeçados pelas organizações, até, por exemplo, a partir da construção de blogs organizacionais específicos, que, com a participação dos públicos, possam levantar a discussão e a reflexão acerca das práticas sociais e ambientais protagonizadas ou apoiadas pelas organizações privadas.

Ao público, cabe assumir uma postura de vigilante perante a organização que se autointitula como socialmente responsável (seja por meio de seus sites ou de outras estratégias de comunicação), investigando seu histórico e sua conduta no plano prático. Em alguns casos, a responsabilidade social, por mais que aparente ser íntegra, pode mascarar, por exemplo, atividades organizacionais que prejudicam a natureza ou mesmo podem esconder a remuneração injusta dos trabalhadores. Não obstante, caso a responsabilidade social organizacional se comprove idônea, o público acaba por sentir-se à vontade para prestigiar essa organização e colaborar com suas ações, bem como a consumir seus produtos ou serviços. 


\section{Referências}

BUENO, W. da C. Comunicação empresarial: teoria e pesquisa. São Paulo: Manole, 2003.

BUENO, W. da C. Comunicação empresarial no Brasil: uma leitura crítica. São Paulo: Mojoara, 2007.

FONSECA Jr., W. C. da. Análise de conteúdo. In: DUARTE, J.; BARROS, A. (Org.). Métodos e técnicas de pesquisa em comunicação. São Paulo: Atlas, 2005. p. $280-315$.

INSTITUTO BRASILEIRO DE ANÁLISES SOCIAIS E ECONÔMICAS (IBASE). Publique seu balanço social. São Paulo, 2008. Disponível em: <http:/ / www.balancosocial.org.br/cgi/cgilua.exe/sys/start. htm>. Acesso em: 1 set. 2008.

INSTITUTO ETHOS DE EMPRESAS E RESPONSABILIDADE SOCIAL. Conceitos básicos e indicadores de responsabilidade social empresarial. 5. ed. São Paulo: Instituto Ethos, 2007.

INSTITUTO ETHOS DE EMPRESAS E RESPONSABILIDADE SOCIAL. O que é RSA? Responsabilidade Social Empresarial. Disponível em: <http://www1.ethos.org.br/EthosWeb/pt/29/o_ que_e_rse/o_que_e_rse.aspx>. Acesso em: 29 jul. 2010.

MONTEIRO, G. F. A notícia institucional. In: DUARTE, J. (Org.). Assessoria de imprensa e relacionamento com a mídia. São Paulo: Atlas, 2003. p. 140-160.

MOTTA, L. G. Teoria da notícia - as relações entre o real e o simbólico. In: MOULLIARD, M.; PORTO, S. D. (Org.). O jornal: da forma ao sentido. Brasília: Paralelo 15, 1997.

PINHO, J. B. Relações públicas na internet: técnicas e estratégias para informar e influenciar públicos de interesse. São Paulo: Summus, 2003.

Recebido: 31/07/2010

Received: 07/31/2010

Aprovado: 16/09/2010

Approved: 09/16/2010 